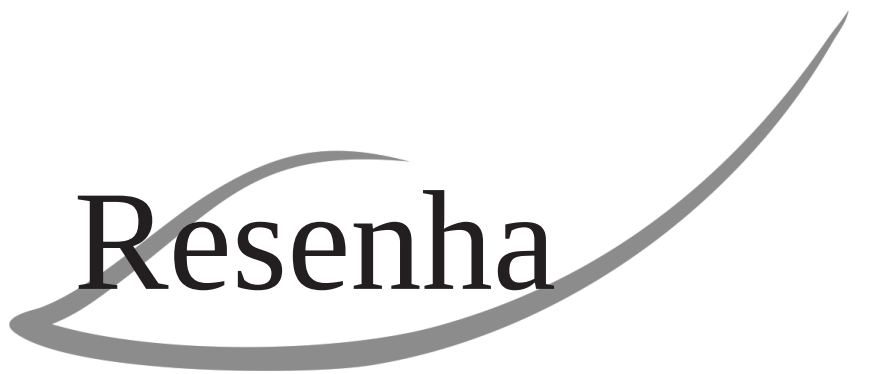




\section{BOURGUIGNON, Jussara Ayres (Org.) Pesquisa social: reflexões teóricas e metodológicas. Ponta Grossa: Todapalavra, 2009.}

O livro, segundo a organizadora, pretende contribuir para a valorização da metodologia no contexto da pesquisa social e demonstrar as possibilidades e potencialidades que esta temática apresenta ao envolver o diálogo interdisciplinar e pluralista. (p. 08)

No primeiro artigo, a relação entre pesquisa e interdisciplinaridade é discutida a partir de alguns desafios enfrentados mais particularmente nas ciências humanas e sociais. A discussão está alicerçada tanto em conceitos como em registros de experiências expressas em bibliografia a respeito do tema e, ainda, em experiência vivenciada pelos autores. Para os autores, Divanir Eulália Naréssi Munhoz e Constantino Ribeiro de Oliveira Júnior, a pesquisa é uma prática teórica que vincula pensamento e ação; nada pode ser intelectualmente um problema, se nãotiver sido, emprimeirolugar, umproblema da vida prática. A interdisciplinaridade é um ponto de partida metodológico para trabalhar com a complexidade do conhecimento, pois é na união de duas ou mais áreas do conhecimento não pertencentes à mesma classe que ocorre o avanço das fronteiras da ciência e da tecnologia. Esse avanço se dá por meio da transferência de métodos de uma área para a outra, gerando novos conhecimentos ou novas disciplinas, podendo fazer surgir um novo profissional com um perfil diferenciado e com uma formação de base sólida e integradora ao mesmo tempo. Os autores afirmam que a concretização de estudos interdisciplinares, além de propiciar a incursão do pesquisador por diferentes áreas do conhecimento, coloca o diálogo entre olhares diversos sobre um mesmo objeto de estudo à disposição de sujeitos concretos, representantes de diferentes profissionais. O texto mostra, portanto, que estudos interdisciplinares são possíveis.

O segundo trabalho - "Teoria, grounded theory e análise qualitativa” -, de Will Gibson e Andrew Brown, faz uma distinção entre duas abordagens: teoria de cima para baixo e teoria de baixo para cima. Na teoria de cima para baixo os pesquisadores usam abordagens conceptuais ou teóricas pré-formulados para classificar, caracterizar e dar sentido ao mundo social. A teoria é trazida de fora para informar ou guiar o formato da pesquisa e organizar o trabalho com os dados. Na teoria de baixo para cima o objetivo é desenvolver estruturas analíticas e concepções teóricas através de análise, ou a utilização de dados para interrogar a teoria. Nela encontram-se pesquisadores que se instituem como criadores de teorias através de suas pesquisas, ou como geradores e esclarecedores de conceitos através da análise de dados. A pesquisa social envolve ambas as práticas, ou seja, uma especificação de ideias teóricas em relação a um corpo de trabalho existente e o exercício dessas ideias em relação aos dados. Essas duas categorias da teoria podem ser tomadas como um recurso para o trabalho obter sentido.

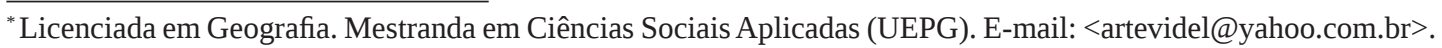


No terceiro artigo, "Considerações sobre o Estudo de Caso na Pesquisa Qualitativa”, Gisele Alves de Sá Quimelli mostra que para o estudo de caso não existe uma receita pronta. A autora traz para a discussão vários autores, expondo o que é o estudo de caso na visão de cada um. Esclarece que, nos Estudos de Caso, uma série de diferentes métodos para coletar e analisar dados pode ser escolhida, e que "optar por uma abordagem de Estudo de Caso não significa uma decisão metodológica voltada a uma direção específica” (p. 67). Quimelli compartilha da definição de André, ao indicar o Estudo de Caso enquanto estratégia de pesquisa de um fenômeno particular contemporâneo, a partir de uma investigação empírica e múltiplos métodos de coleta de dados. A autora defende a necessidade, no Estudo de Caso, de flexibilidade e adaptação por parte do pesquisador, clareza na construção das perguntas e problemas e, especialmente, posicionamento ético na pesquisa. Os objetivos da pesquisa, bem como as condições de realização e, até mesmo, as possíveis implicações posteriores da mesma devem ser discutidos com o informante, o qual tem o direito de abandonar a investigação a qualquer tempo.

A questão é saber como utilizar fontes de evidências para coletar dados, particularmente através de questionários, entrevistas e observações, sem prejudicar informantes ou, mais genericamente, ser desrespeitoso para com eles de alguma maneira.(p.75)

Entretanto, a simples coleta de dados não é suficiente. Faz-se necessária uma tentativa de explicar os fenômenos observados: "o pesquisador deve refletir, comparar e contrastar temas significantes que emergem da coleta de dados." (p.77). Nos Estudos de Caso, não se esperam conclusões bem definidas, mas antes a consideração das con- tradições e complexidades inerentes à vida social.

Édina Schimanski, no artigo intitulado "Pesquisa-ação como instrumento de pesquisa social crítico emancipatória”, propões uma discussão sobre a pesquisa-ação. Para a autora, esse tipo de pesquisa "representa uma forma inovadora de produção de conhecimento cientifico" (p. 85), por trazer elementos diferenciados para a compreensão e construção do conhecimento. Tem como fundamento a emancipação dos sujeitos, é desenvolvida pelos próprios sujeitos de estudo, permitindo a eles a compreensão e intervenção na realidade; e, por suas características peculiares, tem uma forma particular de coleta e análise dos dados. Schimanski aborda em seu texto as origens históricas da pesquisa-ação, porém seu foco está no instrumento crítico-reflexivo e emancipatório desse tipo de pesquisa para o protagonismo dos sujeitos. A pesquisa-ação "deve ser uma proposta de intervenção política e social no contexto de produção do conhecimento humano e social” (p.97).

O quinto artigo, cujo título é "Pesquisa etnográfica: elementos essencias”, foi escrito por Jefferson Mainardes. O texto apresenta os elementos essencias da pesquisa etnográfica, destacando que na atualidade a etnografia vem sendo bastante empregada nas Ciências Sociais e Humanas e que tem havido um intenso debate dos aspectos epistemológicos e metodológicos desse tipo de pesquisa. $\mathrm{O}$ autor se baseia em Coehen et al. (2000) para descrever os estágios da pesquisa etnográfica, que são: a) identificação dos problemas; b) definição do foco de pesquisa; c) delineamento das questões e delineamento da pesquisa; d) definição da amostra e das estratégias de coleta de dados. A pesquisa etnográfica pode ser realizada em uma variedade de lugares: cidades de diferentes portes, regiões periféricas, fábricas, minas, 
fazendas, escritórios, empresas, hospitais, prisões, igrejas, escolas, universidades, etc. Mainardes aborda o surgimento da etnografia crítica, que traz uma nova roupagem à etnografia, pois impulsiona o pesquisador a tomar um posicionamento diante da realidade que está sendo investigada e, na medida do possível, indicar estratégias que possam ser úteis para a transformação da realidade, principalmente quando se trata de situações de exclusão, injustiças e opressões, sem se descuidar das questões éticas que envolvem o sujeito da pesquisa.

No sexto artigo, "Métodos quantitativos nas ciências sociais: uma abordagem alternativa ao fetichismo dos números e ao debate com qualitivistas", de Emerson Urizzi Cervi, o autor traz à discussão o papel dos métodos quantitativos como ferramenta empírica nas ciências sociais. Expõe que

o quantitativismo tem seu lugar na ciência por se tratar de um conjunto de técnicas de pesquisa social e análise que, ao ser bem aplicado, permite relacionar descobertas sobre padrões de comportamento social com implicações nas teorias sociais já existentes. (p. 125)

Para que isso ocorra, é necessário evitar certas armadilhas, como: o excesso de quantitativismo que transforma a ferramenta estatística em finalidade última da pesquisa empírica, em vez de utilizála para o acesso à realidade social; e o debate estéril entre quantitativistas e qualitativistas, que procuram escolher entre ambas a melhor técnica de pesquisa. Para o autor, o método adequado depende do objeto de análise. Cervi apresenta os debates conceituais que definem o conceito e caracterizam os métodos quantitativos, em especial nas ciências sociais. Para finalizar, descreve as principais técnicas de coleta de dados e análises empíricas relacionadas ao quantitativo disponível à comunidade científica para a produção de estudo sobre a realidade social.

O sétimo artigo - "Pesquisa qualitativa inter e transdisciplinar: uma abordagem complexa da família e deficiência” - é de autoria de Fátima Gonçalves Cavalcante e Maria Cecília Minayo. No texto, as autoras abordam uma lógica de construção e de aplicação metodológica que possibilita um olhar psicossocial e antropológico do fenômeno família e deficiência. Cavalcante e Minayo pensam a deficiência como um fenômeno da vida e a família como uma construção social, propõem uma metodologia que articula ferramentas teórico-conceituais da filosofia da ciência, da linguagem, da antropologia, da fenomenologia do cotidiano e da psicanálise, enriquecendo o campo da saúde e da reabilitação. Trazem uma abordagem que estuda a pessoa como um ser integral no qual predomina o todo sobre as partes; o sujeito é visto como um ser pleno de significado de vida, podendo ser compreendido pela sua singularidade. Ao invés de estudar o sujeito como coisa em si passível de ser desvendada, as autoras propõem estudá-lo como objeto inacabado, em construção, produto de suas condições e contradições históricas, buscando desvendar o ponto de vista da pessoa com deficiência e de sua família numa perspectiva diacrônica, fazendo uma contextualização de época e reconstruindo a biografia familiar, a genealogia, a história institucional com sua evolução e a historia dos tratamentos empreendidos junto ao filho com deficiência. Por fim, as autoras tecem considerações sobre a importância de a pesquisa ter uma abordagem reflexiva que integre diferentes pontos de vistas com uma visão global e não reducionista, privilegiando as manifestações na linguagem, na história, nas emoções e na práxis social. 
O último artigo, de Jussara Ayres Bourguignon, tem como título "O retorno e o alcance das pesquisas desenvolvidas na área social”. Nesse texto ocorre a reflexão do conhecimento produzido nas organizações sociais por meio dos mais diversos profissionais e o resultado para os sujeitos que requisitam a prática desses profissionais. A autora expressa a preocupação do retorno do conhecimento para a comunidade por meio dos profissionais formados na área das Ciências Sociais.

A relevância social de uma pesquisa está em sua capacidade de aprender a realidade e ser referência para os profissionais da categoria e de outras áreas do conhecimento, bem como alimentadoras de práticas críticas. (p.178)

Alcançar a realidade social e o modo de vida dos sujeitos que buscam as práticas profissionais e as estruturas onde estas se desenvolvem é um desafio para o campo do conhecimento científico e da compreensão das transformações societárias. É preciso pensar em estratégias capazes de estreitar vínculos entre diversos tipos de pesquisadores e chegar até as demandas sociais concretas da população. Para a autora, o conhecimento produzido deve estar à disposição da população e possibilitar aos sujeitos condições de superar os entraves do desenvolvimento social e humano.

Ao ter apresentado os artigos componentes do livro, é necessário realizar uma análise do mesmo em seu conteúdo geral. $\mathrm{O}$ ponto central do livro dirige-se à pesquisa social e à questão teórico-metodológica investigada e exposta pelos autores. $\mathrm{Na}$ apresentação, a organizadora do livro, Professora Dra. Jussara Ayres Bourguignon, afirma que a coletânea apresenta os textos de forma a articular as discussões teóricas e metodológicas, buscando superar qualquer possibilidade de fragmentação, o que foi plenamente realizado nos artigos. Diz, também, que a publicação pretende estimular a troca de conhecimento, motivando diálogos fecundos, interdisciplinares e geradores de novas produções sobre Metodologia de Pesquisa, o que acreditamos ser totalmente possível pela qualidade dos textos.

Os artigos contêm abordagens interdisciplinares e nota-se, neles, uma preocupação com os sujeitos envolvidos na pesquisa, o que proporciona um significado ímpar ao livro. Os oito textos formam uma polifonia harmônica de vozes, em relação ao reconhecimento de aspectos comuns à Pesquisa Social; os artigos fazem evoluções nos seus temas, em diversas escalas, proporcionando a incursão dos mais diferentes profissionais e acadêmicos nas leituras abordadas nos textos.

A coletânea assume a tarefa de "alimentar os pesquisadores da área das Ciências Sociais e Humanas, na graduação e pós-graduação" (p.07). Revela a todos nós, com inteireza, uma parte do universo da pesquisa social com suas diversas metodologias, imprescindível a todo pesquisador.

Convido o leitor a ler, acompanhar e degustar cada parte dessa composição conjunta.

Enviado em: 23/08/2011

Aceito em: 21/12/2011 